Voix et Images

voixetimages

\title{
Le sujet féminin : de l'intime à la mémoire
}

Janet M. Paterson et Nathalie Watteyne

Volume 34, numéro 2 (101), hiver 2009

Louise Dupré

URI : https://id.erudit.org/iderudit/029461ar

DOI : https://doi.org/10.7202/029461ar

Aller au sommaire du numéro

Éditeur(s)

Université du Québec à Montréal

ISSN

0318-9201 (imprimé)

1705-933X (numérique)

Découvrir la revue

Citer cet article

Paterson, J. M. \& Watteyne, N. (2009). Le sujet féminin : de l'intime à la mémoire. Voix et Images, 34(2), 7-10. https://doi.org/10.7202/029461ar d'utilisation que vous pouvez consulter en ligne.

https://apropos.erudit.org/fr/usagers/politique-dutilisation/ 


\title{
LE S UJET Féminin : De L'INTIME À LA MÉmoire
}

\author{
$+++$ \\ JANET M. PATERSON \\ Université de Toronto \\ NATHALIE WATTEYNE \\ Université de Sherbrooke
}

L'importance de Louise Dupré dans le champ littéraire québécois contemporain n'est plus à démontrer. Poète, romancière, essayiste et professeure au Département d'études littéraires de l'UQAM, elle a enseigné la littérature québécoise et la création littéraire de 1988 à 2008. Membre de l'Académie des lettres du Québec et de la Société royale du Canada, elle a cumulé plusieurs prix et distinctions, depuis le prix AlfredDesRochers qu'elle a obtenu en 1984 pour son premier recueil de poèmes, La peau familière. Elle a remporté le Grand Prix du Festival international de poésie de TroisRivières en 1993 pour le recueil Noir déjā, le prix Ringuet de l'Académie des lettres du Québec en 1997 pour le roman La memoria et le deuxième Grand Prix de poésie Radio-Canada en 1997 pour le recueil Tout près. Plus récemment, le spectacle Tout comme elle s'est vu décerner le Prix de la critique pour la saison 2005-2006 par l'Association québécoise des critiques de théâtre, à Montréal. Qui plus est, l'écrivaine a participé à de multiples événements publics et à des rencontres internationales où elle s'est interrogée tant sur l'inscription du féminin que sur les voies de l'intime dans la littérature québécoise.

Livrant avec pudeur un ardent désir de tendresse dans un monde par moments tragique, Louise Dupré a beaucoup écrit et dans des genres littéraires variés: neuf recueils de poésie, deux romans, deux textes pour le théâtre, un recueil de nouvelles, un essai individuel et deux essais collectifs, des livres d'artistes, des poèmes-affiches, des anthologies, sans oublier les directions de dossiers publiés dans des revues. Elle a fait paraître une centaine de textes de création, tant au Québec qu'à l'étranger, traduits dans huit langues. Elle-même a traduit de l'anglais des textes de création d'auteures comme Ann Diamond et Susan Glickman. Elle a fait paraître plus de soixante-quinze articles et comptes rendus dans les revues et journaux, notamment dans La Nouvelle Barre du jour, une revue à laquelle elle a souvent collaboré entre 1978 et 1989. Mais c'est au sein du comité de lecture des Éditions du remue-ménage qu'elle s'est surtout engagée, maison où sont parus la pièce de théâtre collective Si Cendrillon pouvait mourir! en 1980, trois recueils de poèmes, soit La peau familière en 1983, Chambres en 1986 et Bonheur en 1988, et deux essais, dont Stratégies du vertige, trois poètes: Nicole Brossard, Madeleine Gagnon, France Théoret en 1989. 
Très commentée, l'œuvre a fait l'objet d'une monographie ${ }^{1}$, d'une thèse de doctorat et de quatre mémoires de maîtrise. On ne compte plus les recensions, entretiens et portraits dans les journaux, et les articles de fond dans des revues universitaires. Outre ses textes de création, qui s'adressent à divers publics, les essais sur l'écriture des femmes, la réflexion sur le Montréal des écrivains et sur les ateliers de création intéressent les critiques.

Forte de sa conscience historique et de sa connaissance de l'écriture des femmes au Québec, Louise Dupré n'a eu de cesse, depuis la création collective de sa première pièce de thêâtre, représentée à l'occasion de la Journée internationale des femmes, le 8 mars 1975, et la publication de son premier article sur «L'urgence d'une critique féministe» en 1979, d'interroger, au thêâtre, en poésie comme en prose, l'ancrage dans le réel d'un sujet féminin. S'intéressant aux poètes des années 1920 et 1930, et plus particulièrement à Simone Routier, poète de l'intime à laquelle elle consacre une anthologie en $2005^{2}$, ainsi qu'à la génération plus engagée et militante des années 1970, celle des Nicole Brossard, Madeleine Gagnon et France Théoret, Louise Dupré a également placé le féminin au centre de sa démarche créatrice et elle a inscrit sa poétique dans un rapport de filiation à d'autres femmes. Appartenant à la génération des années 1980 marquée par l'exploration de formes neuves, puis par la poésie du quotidien, elle a choisi, à l'instar d'Anne-Marie Alonzo et de Denise Desautels, d'adopter un ton discret, de conjuguer l'affirmation de soi et l'ouverture à autrui. Par le travail de la chair et de l'inconscient, l'autre est rejoint dans son humanité selon des modalités qui renvoient au maternel, comme elle le formule ellemême au moment de rendre compte de l'écriture de Madeleine Gagnon: «Il ne s'agit pas seulement de faire surgir le maternel dans les rythmes, les sonorités, les figures, mais de représenter "le non-représentable", de le faire entrer dans le symbolique ${ }^{3}$."

Tout en se situant par rapport à la mère, le personnage féminin, solitaire et fragile, endeuillé, fait l'épreuve de la noirceur et de la douleur, traverse doutes et angoisses pour retrouver le goût de vivre à l'occasion d'un voyage ou d'une rencontre amoureuse. L'évocation de la folie des uns, de la barbarie des autres et de l'horreur qu'inspire l'histoire permet d'associer une dimension collective à l'histoire individuelle. Un peu de paix sera acquise après l'acceptation du fait que le noir fait partie de la vie. Loin de chercher refuge dans le repli nostalgique, le sujet se transforme au gré des rencontres, après avoir fait l'expérience de la dévastation dans sa quête d'autonomie et sa marche vers un bonheur simple. Tel est bien le nœud qui se défait au moyen d'une écriture vivante, logée au cœur des paradoxes: ce n'est pas en contournant la figure de la mère, mais bien en la convoquant, que l'on parvient à s'en séparer. De même, c'est en accueillant la douleur que l'on arrive à colmater ses blessures personnelles. Le travail de la mémoire est un aspect central de la poétique de Louise Dupré qu'elle va développer tant dans ses deux romans, La memoria et

$$
+++
$$

1 Un ouvrage, issu de la thèse de doctorat d'Anne-Marie Jézéquel, vient ainsi de paraître: Louise Dupré. Le Québec au féminin, Paris, L'Harmattan, 2008, 270 p. 2 Simone Routier, Comment vient l'amour et autres poèmes, choix et présentation de Louise Dupré, Montréal, Les Herbes rouges, coll. «Five o'clock», 2005, 155 p. 3 Louise Dupré, "Sujet féminin, sujet lyrique», Nathalie Watteyne (dir.), Lyrisme et énonciation lyrique, Québec/Bordeaux, Nota bene/Presses universitaires de Bordeaux, 2006, p. 195. 
La Voie lactée, que dans ses nouvelles, dont certaines viennent d'être réunies dans L'été funambule.

Ce sont les qualités particulières de cette écriture que nous voulons examiner dans le présent dossier, les formes qu'elle emprunte, tant dans ses vers qu'en prose, qui rendent manifestes le souci du détail et l'attention minutieuse portée au dispositif langagier. En poésie, l'alternance de la prose et des vers, et en prose, une construction narrative épurée chargent de sens, dans une langue précise, la vie de tous les jours dans un monde où il faut bien vivre, et où l'horreur côtoie de fugitifs bonheurs. L'image récurrente de la fenêtre sert bien l'émotion du sujet, capable aussi bien de se retrancher dans son intériorité que de sortir et d'aller à la rencontre d'autrui. La gravité mélancolique, l'exploration de la douleur archaïque ou historique n'empêchent pas un profond désir de lumière, bien au contraire. Le fantasme et la mémoire du corps participent de la sorte à la lecture des destins singuliers: on s'assure de sa présence au monde par l'expérience perceptive et sensuelle et par l'intuition des drames d'autrui, tout en se remémorant les affres du passé qui continuent d'exercer une emprise sur le présent. Le sens intime constitue l'ancrage et le repère le plus sûr d'un moi fragile et lucide.

On mesurera toute l'importance de la réminiscence et du souvenir fantasmé dans le texte inédit "La porte fermée», que Louise Dupré nous offre ici. L'histoire personnelle et collective du sujet, qui n'a d'autre choix que de composer avec l'horreur de la guerre, est rendue avec subtilité à travers les motifs du voyage, de l'art et de l'amitié. On y retrouve à Munich des étrangers, parmi lesquels deux femmes, l'une, universitaire et touriste, l'autre, artiste et guide, avec leur désir d'art et leur exigence de vérité, leur déception face à l'histoire, de même que leur perplexité face à l'oubli. Tout cela est livré dans une prose dépouillée qui ranime nos traumatismes anciens, par la trace et l'archive qui évoquent la Seconde Guerre mondiale et qui prêtent à une méditation sur la barbarie et la cruauté humaines. Vie et mort se disent ainsi par le dépaysement et le familier.

Les articles de ce dossier explorent différents aspects de l'œuvre de Louise Dupré. André Brochu fait une lecture d'ensemble de la poésie, pour en dégager les transformations sémantiques et formelles. D'une trajectoire poétique qui s'étend sur une vingtaine d'années, il fait ressortir une évolution, qui va du formalisme et du féminisme à une écriture qui reste précise et engagée, mais de plus en plus harmonieuse et limpide. Ce faisant, il met au jour les grands thèmes de cette poésie: de la valorisation du détail aux modalités de l'intime en passant par une méditation sur la douleur et le bonheur. C'est à la lumière des cycles de la vie et de la mort que Denise Brassard examine le fonctionnement poétique de six recueils, où la parole oscille entre le devoir de la mémoire et la tentation de l'oubli. Par l'entremise des figures liminales de la mère, du corps et du geste, cette oscillation donne forme au texte. L'expérience du déchirement et du vieillissement prête à un accueil du paysage perçu à travers une fenêtre ou lors d'une promenade, accueil qui se transforme bientôt en exigence de recueillement lucide. Jaap Lintvelt, pour sa part, se penche sur les deux romans de Louise Dupré, La memoria et La Voie lactée, pour en analyser le processus de renouvellement intérieur. Les deux protagonistes féminins, Emma et Anna, aux prises avec un passé traumatisant, sont en quête d'une reconstruction identitaire. 
Jaap Lintvelt explique que cette reconstruction est tributaire de leur expérience du temps et de l'espace. Passant de l'enfermement à l'ouverture, du temps de l'attente à celui du renouvellement, les personnages se réinventent littéralement et métaphoriquement une nouvelle identité. Sandrina Joseph s'intéresse elle aussi aux deux romans, pour y étudier l'importance du minime, du presque rien et du familier. Avançant que Louise Dupré élabore, dans son œuvre, une poétique du tout petit et du vécu, elle en analyse les représentations les plus saisissantes. Le détail, les objets, voire le banal sont précisément ce qui permet aux protagonistes Emma et Anna de délier l'emprise des souvenirs douloureux pour construire un nouveau quotidien marqué de gestes ordinaires. En prenant comme point de départ les quarante-huit scènes qui composent Tout comme elle, Nathalie Watteyne soutient que la dynamique du texte tient à sa capacité de rendre visibles les liens complexes entre mère et fille par la parole, le non-dit et le silence. Pour la fille adulte, la mère, jadis idéalisée, est remplacée par une personne vieillissante et désœuvrée dont les silences comme les paroles sont fréquemment lourds, sinon chargés de violence. Et le cycle de continuer de mère en fille, de génération en génération jusqu'à ce que, comme le démontre Nathalie Watteyne, une distance mesurée et une douleur partagée permettent à la fille et à la mère de retrouver connivence et amour. Un entretien complice avec Janet Paterson et une riche bibliographie complètent ce tour d'horizon.

Dans ses poèmes comme dans ses romans, dans ses textes pour le théâtre comme dans ses essais, Louise Dupré module, depuis plus d'un quart de siècle, des voix féminines et des voies de l'intime dans la littérature québécoise. À la fois sobre et saisissante, sereine et blessée, son écriture dévoile une quête de lucidité et de bonheur face à l'angoisse du monde ${ }^{4}$.

4 Afin d'alléger le système de notes, les sigles, suivis des folios renvoyant aux œuvres de Louise Dupré mentionnées dans ce dossier, seront placés entre parenthèses dans les textes: La peau familière ( $P F)$, Montréal, Les Éditions du remue-ménage, 1983, 127 p.; Où (O), Éditions de La Nouvelle Barre du jour, coll. «On voit plus de prodiges merveilleux \& de belles choses ", 1984, 21 p. ; Chambres (C), Montréal, Éditions du remue-ménage, coll. "Connivences», 1986, 93 p. [Réédition en format poche: Montréal, Éditions du remue-ménage, 1996, 90 p.] ; "Quand on a une langue on peut aller à Rome» (QOAL), avec Normand de Bellefeuille, Montréal, Éditions de La Nouvelle Barre du jour, coll. «Auteur/e», 1986, 62 p.; Bonheur (B), Montréal, Éditions du remue-ménage, coll. «Connivences», 1988, 103 p.; Noir déjà (ND), Montréal, Éditions du Noroît, 1993, 94 p.; Tout près (TP), Montréal, Éditions du Noroît, 1998, 95 p. ; Les mots secrets (MS), Montréal, La Courte Échelle, coll. "Poésie», 2002, 39 p.; Une écharde sous ton ongle (ESTO), Montréal, Éditions du Noroît, 2004, 100 p.; La memoria (M), Montréal, XYZ éditeur, coll. «Romanichels», 1996, 219 p. [Réédition: Montréal, XYZ éditeur, coll. «Romanichels poche», 1997, 213 p.]; La Voie lactée (VL), Montréal, XYZ éditeur, coll. «Romanichels», 2001, 199 p.; Si Cendrillon pouvait mourir! (SC), création collective, Montréal, Éditions du remue-ménage, 1980, 79 p.; Tout comme elle, suivi d'une conversation avec Brigitte Haentjens (TE), Montréal, Québec Amérique, coll. "Mains libres», 2006, 110 p. ; L'été funambule (EF), Montréal, XYZ éditeur, coll. «Romanichels», 2008, 156 p. 